Trivent Publishing

(C) The Authors, 2016

Available online at http://trivent-publishing.eu/

Engineering and Industry Series

Volume Power Systems, Energy Markets and Renewable Energy Sources in

South-Eastern Europe

\title{
The Effect of Pumped Hydro Storage Units Installation on the Operation of the Autonomous Cretan Power System
}

\author{
Y. A. Katsigiannis, ${ }^{1}$ E. S. Karapidakis ${ }^{1}$ \\ ${ }^{1}$ Technological Educational Institute of Crete, Department of \\ Environmental and Natural Resources Engineering, Chania, Greece, \\ katsigiannis@chania.teicrete.gr, karapidakis@chania.teicrete.gr
}

\begin{abstract}
Pumped hydro storage (PHS) units represent the most mature technology for large scale energy storage. The ideal criteria for a PHS unit installation include: (a) the existence of an autonomous power system with local power stations, (b) the current high electricity production cost, (c) the high potential of renewable energy sources (mainly wind), and (d) the non-flat terrain morphology. Cretan power system represents an ideal case for the installation of PHS units, as it fulfils all of the above criteria. This paper shows the effect of the installation of a planned PHS unit in Malia, Heraklion, Crete. The calculations are based on real data provided by the Cretan power system operator, whereas the results show the effect of PHS units operation on the energy mix, as well as the economic viability of the project which is combined with significant environmental benefits.
\end{abstract}




\section{Keywords}

Autonomous power systems; energy storage; pumped hydro storage; renewable energy sources.

\section{Introduction}

The Greek power system consists of the mainland interconnected system, which consumes the largest portion of total electricity demand $(\approx 90 \%)$, and a large number of autonomous power systems, with the vast majority of them located in the islands of the Aegean Archipelago [1]. In most of these systems, the cost of electricity production is much higher than in interconnected systems due to the high operating costs of their thermal generating units, mainly diesel and gas turbines, and the import and transportation costs of the fuel used.

The majority of these autonomous islands present significant wind and solar potential, which make the exploitation of these renewable energy sources (RES) ideal by using technologies such as wind turbines (WTs) and photovoltaics (PVs); significant progress has been made till now. These technologies, when installed properly, may provide significant benefits to the system [2]. Unfortunately, production fluctuation from RES may not match the demand. Usually, the demand is higher in early night hours, with simultaneous decrease in wind power production.

In such systems, contrary to interconnected ones, mismatches in generation and load and/or unstable system frequency control might lead to system failures much easier. Increased share of intermittent RES, may be economically attractive [3] but unless special precautions are made, the dynamic security of the whole system may deteriorate [4].

Energy storage may be an interesting solution to alleviate technical barriers for increasing intermittent RES penetration. One of the main disadvantages of energy storage is its high initial cost. However, when sized properly, energy storage can provide an economically-viable solution, especially in the cases of autonomous power systems that present high operating costs.

Although many technologies are available for energy storage, pumped hydro storage (PHS) represent the most mature technology for large-scale energy storage. This paper shows the effect of the installation of a planned PHS unit in Malia, Heraklion, Crete. The paper is organized as follows: Section II contains a description of the Cretan power system. A brief presentation of PHS technology is included in Section III. Section IV describes the unit commitment problem for Cretan power system. Section V contains the main considerations and results of the analysis, whereas Section VI concludes the paper. 


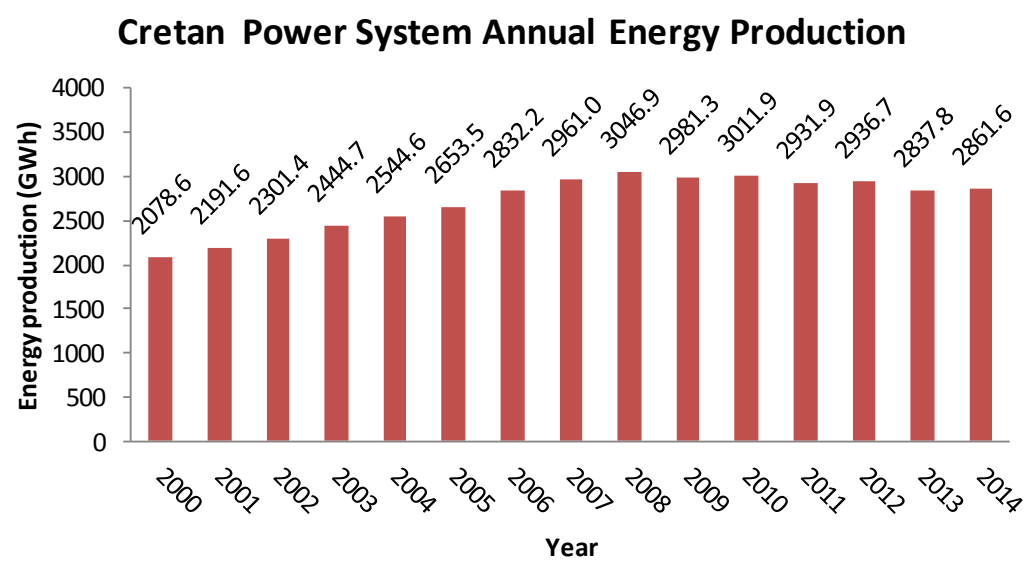

Fig. 1. Annual energy production of Cretan power system.

\section{Cretan power system}

Crete is the largest Greek island with approximately $8500 \mathrm{~km}^{2}$ and the fifth in Mediterranean Sea with more than 600,000 inhabitants, tripling in summer period. It is also the largest isolated system in Greece. Additionally, considerable annual increase of electricity demand, up to $7 \%$, had been noted during the period 2000-2008 (see Fig. 1). As a result, the annual energy production during 2008 exceeded 3TWh, compared to the modest $485 \mathrm{GWh}$ of year 1980. However, during the last years (2008-2014), electricity production has remained steady between 2.8 and $3 \mathrm{TWh}$.

Electricity generation system is based mainly on oil-fired thermal power units. A large number of conventional units with different technology and response characteristics (steam turbines, diesel generators, gas turbines, and one combined cycle unit) in three power plants with total capacity of 783MW have been installed as described in Table 1 . The steam and diesel units mainly supply the base-load. The gas turbines normally supply the daily peak load or the load that cannot be supplied by the other units in outage conditions. These units have a high running cost that increases significantly the average cost of the electricity being supplied. 
Table 1. Installed capacity (in MW) per unit type and power station

\begin{tabular}{|l|c|c|c|c|}
\hline Power station & Steam & Diesel & Gas & CC \\
\hline Linoperamata & 106 & 44 & 115 & - \\
\hline Chania & - & - & 206 & 126 \\
\hline Atherinolakos & 86 & 100 & - & - \\
\hline Total capacity & 192 & 144 & 321 & 126 \\
\hline
\end{tabular}

On the island, in many locations average wind speed is higher than $8.5 \mathrm{~m} / \mathrm{sec}$. Moreover, Crete presents one of the highest solar potentials in whole Europe reaching up to $2100 \mathrm{kWh} / \mathrm{m}^{2} / \mathrm{yr}$ [5]. These characteristics make Crete ideal for the installation of wind and solar technologies. As a result, already 33 wind farms have been installed with rated power of 187.1MW. Additionally, more than 1000 small PV parks (mainly of $80 \mathrm{~kW}$ each) and 1800 roof PVs have been installed, reaching a total of $95.5 \mathrm{MW}$ [6]. Table 2 presents the percentage of annual energy production in 2014 for all installed units of the island (conventional and RES), in which RES penetration exceeds $20 \%$.

Table 2. Characteristics of Crete Island's electricity units (year 2014)

\begin{tabular}{|l|c|c|}
\hline Technology & Fuel & Annual electricity production share \\
\hline Steam turbines & Mazut & $36.70 \%$ \\
\hline Diesel generators & Mazut & $24.85 \%$ \\
\hline Gas turbines & Diesel & $3.85 \%$ \\
\hline Combined cycle (CC) & Diesel & $14.47 \%$ \\
\hline WTs & - & $15.03 \%$ \\
\hline PVs & - & $5.11 \%$ \\
\hline
\end{tabular}

\section{Description of PHS systems}

A wide variety of energy storage technologies are commercially available and include PHS systems, rechargeable batteries, flow batteries, and compressed air. Potential benefits include capacity reduction, frequency support, standing reserve provision and blackstart capability. Depending on technical requirements and geographical settings, a particular utility may avail of one or more of these technologies. Research effort has also focussed on ultracapacitors, high-speed flywheels and superconducting magnetic energy storage. While these are highly responsive, their energy storage capabilities are limited, making such approaches more suitable for power quality applications and for improving system reliability.

The most widely established large-scale form of energy storage is PHS. Typically, such plant operates on a diurnal basis - charging at night during periods of low demand (and low-priced energy) and discharging during times of 
high or peak demand. A PHS plant may have the capacity for 4-8 hours of peak generation with 1-2 hours of reserve, although in some cases the discharge time can extend to a few days. Worldwide capacity is almost $100 \mathrm{GW}$, with facilities ranging up to 2,000 MW. The high construction costs, long development times and environmental considerations (most feasible locations are already being exploited) suggest that future growth in this area will be limited. Traditionally, PHS is utilised for energy management and the provision of standing reserve, but more recent installations possess the ability to provide frequency support and operate at partial capacity [7].

Hydroelectric plants typically have fast ramp-up and ramp-down rates, providing strong regulating capabilities, and their marginal generation cost is close to zero. In many countries, a natural synergy exists between hydroelectric generation/pumped storage and wind power. Clearly, if hydro generation is being replaced by wind energy then emission levels will not be directly affected, but the hydro energy can be transformed into potential energy stored for later use. The existing hydroelectric plant can reduce their output, using the reservoirs as storage, to avoid wind energy curtailment.

PHS systems usually consist of the following parts: an upper reservoir, waterways, a pump, a turbine, a motor, a generator and a lower reservoir, shown schematically in Fig. 2.

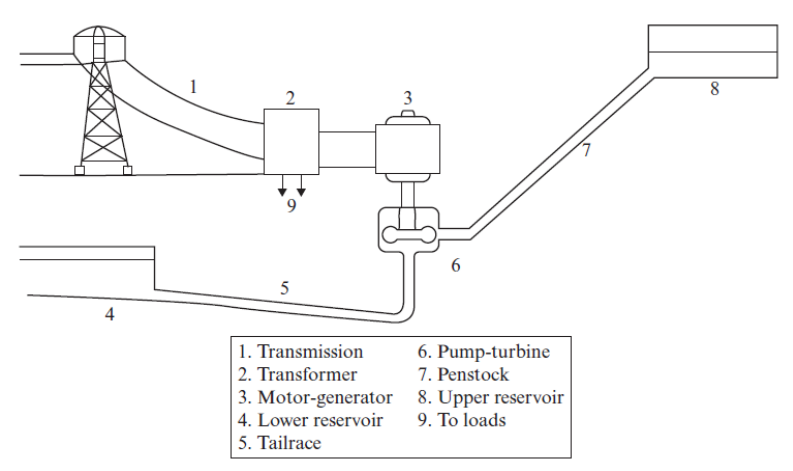

Fig. 2. Structure of a PHS system [8]

As in any hydraulic system, in PHS there are losses during operation, such as frictional losses, turbulence and viscous drag, and the turbine itself is not $100 \%$ efficient. The water retains some kinetic energy even when it enters the tailrace. For the final conversion of hydro power to electricity, generator losses have to be also accounted. The overall efficiency of a PHS system is defined as the ratio 
of the energy supplied to the consumer while generating, and the energy consumed while pumping, and it usually lies in the range of $70-85 \%$.

\section{Unit commitment}

Unit commitment is a very significant optimization task, which plays a major role in the daily operation planning of power systems, especially in the framework of the deregulated power markets. The objective of unit commitment is to minimize the total operating cost of the generating units during the scheduling horizon, subject to a number of system and unit constraints. The overall problem can be divided into two subproblems: the mixed-integer nonlinear programming problem of determining the on/off state of the generating units for every hour of the dispatch period (usually 24 hours) and the quadratic/cubic programming problem of dispatching the load among them. The simultaneous solution of both problems is a very complicated procedure, the difficulty of which grows proportionally to the number of units and constraints taken into consideration [9] [10].

Table 3. Technical characteristics and priority list of thermal units in Cretan power system

\begin{tabular}{|l|c|c|c|}
\hline Thermal Unit & Priority list & $\mathbf{P}_{\min }(\mathbf{M W})$ & $\mathbf{P}_{\max }(\mathbf{M W})$ \\
\hline Steam 2 Linoperamata & 1 & 8 & 14 \\
\hline Steam 3 Linoperamata & 2 & 8 & 14 \\
\hline Steam 4 Linoperamata & 3 & 18 & 24 \\
\hline Steam 5 Linoperamata & 4 & 18 & 24 \\
\hline Steam 6 Linoperamata & 5 & 18 & 24 \\
\hline CC (unit 1) Chania & 6 & 17.5 & 63 \\
\hline Steam 1 Atherinolakos & 7 & 22 & 43 \\
\hline Steam 2 Atherinolakos & 8 & 22 & 43 \\
\hline CC (unit 2) Chania & 9 & 17.5 & 63 \\
\hline Diesel 1 Atherinolakos & 10 & 35 & 50 \\
\hline Diesel 2 Atherinolakos & 11 & 25 & 50 \\
\hline Diesel 1 Linoperamata & 12 & 3 & 11 \\
\hline Diesel 2 Linoperamata & 13 & 3 & 11 \\
\hline Diesel 3 Linoperamata & 14 & 6 & 11 \\
\hline Diesel 4 Linoperamata & 15 & 3 & 11 \\
\hline Gas 3 Linoperamata & 16 & 5 & 43 \\
\hline Gas 13 Chania & 17 & 5 & 28 \\
\hline Gas 5 Linoperamata & 18 & 5 & 28 \\
\hline Gas 11 Chania & 19 & 10 & 58 \\
\hline Gas 12 Chania & 20 & 10 & 58 \\
\hline Gas 4 Linoperamata & 21 & 3 & 14 \\
\hline Gas 5 Chania & 22 & 5 & 28 \\
\hline
\end{tabular}




\begin{tabular}{|l|c|c|c|}
\hline Gas 2 Linoperamata & 23 & 3 & 15 \\
\hline Gas 1 Chania & 24 & 3 & 14 \\
\hline Gas 4 Chania & 25 & 3 & 20 \\
\hline Gas 1 Linoperamata & 26 & 3 & 15 \\
\hline Steam 1 Linoperamata & 27 & 4 & 6 \\
\hline Total & - & 283 & 783 \\
\hline
\end{tabular}

The total operating cost of the generating units consists of:

- Fuel costs

- Start-up costs

- Shut-clown costs

Fuel costs are calculated using unit heat rate and fuel price information. The use of dual fuels for flame stabilization when the unit operates at low output levels, for example during start up ramps, further complicates the fuel cost computation. Start-up costs are expressed as a function of the number of hours the unit has been down (exponential when cooling and linear when banking). Shut-down costs are defined as a fixed amount for each unit per shut-down. The constraints which must be satisfied during the optimization process are [11]:

- System constraints: They include system power balance (demand + losses + exports), and system reserve requirements

- Local constraints: They include unit initial conditions, unit high and low power limits (economic, operating), unit minimum-up time, unit minimum-down time, unit status restrictions (must-run, fixed-MW, unavailable, available), unit rate limits, unit start-up ramps, unit shut-down ramps, unit flame stabilization fuel mix, unit dual or alternate fuel usage, unit or plant fuel availability, and plant crew constraints

The basic solution methods of unit commitment problem include the priority list method, dynamic programming, branch-and-bound, Lagrangian relaxation, and numerous artificial intelligence methods. In Cretan power system, the priority list method is used, which mimics the scheduling practices followed by system operators. The units are committed in ascending order of the unit average full load cost so that the most economic base load units are committed first and the peaking units last in order to meet the load demand. Priority list methods are very fast but they are highly heuristic and give schedules with relatively high production costs. Table 3 presents the main technical characteristics and priority list for Cretan power system's thermal (conventional) units. 


\section{Considerations and results}

\section{A. Description of studied PHS}

The PHS system of Malia will have the ability to provide guaranteed power through 3 hydro turbines with an installed capacity of $25 \mathrm{MW}$ each (as a corresponding hydro power station with nominal output of $75 \mathrm{MW}$ ) for 8 hours per day, producing $600 \mathrm{MWh}$ daily. This PHS station is sited in a mountainous area of Malia, Heraklion, Crete. In parallel, the PHS system has 4 wind farms (WFs) in the prefectures of Chania and Rethymno, with total capacity of 166MW. This capacity will be limited to 120MW during wind farm production, following the Greek legislative framework. The main technical characteristics of Malia PHS are presented Table 4.

Table 4. Main technical characteristics of Malia PHS

\begin{tabular}{|l|c|}
\hline Wind Farms & \\
\hline Total Installed Capacity & $166 \mathrm{MW}$ \\
\hline Maximum Permitted Capacity (Injected) & $120 \mathrm{MW}$ \\
\hline Pumping \& Hydroelectric Station & \\
\hline Pumps (8 pumps x 12.5MW) & $100 \mathrm{MW}$ \\
\hline Hydroelectric station (installed capacity) & $100 \mathrm{MW}$ \\
\hline Hydroelectric station (guaranteed capacity) & $75 \mathrm{MW}$ \\
\hline Upper \& Lower reservoir tank (total storage) & $1250 \mathrm{MWh}$ \\
\hline Upper \& Lower reservoir tank (actual storage) & $1100 \mathrm{MWh}$ \\
\hline
\end{tabular}

According to the operational code of Cretan power system [12], the PHS submits an overall daily bid of energy supply, which is available to offer in the network for the next day ( 24 hours time interval). By this action, the network administrator is required to absorb this energy supply prior to the energy produced by conventional units, as energy produced by RES technologies.

Furthermore, in cases that the network administrator considers that more power is needed to meet the power demand that cannot be satisfied by other production units, only then can he require from the PHS to provide the next day into the grid part or the whole of its capacity in "guaranteed energy." More specifically, in this case if the PHS is not able to provide the required stored energy in order to adequately meet the given requirement and cannot cover it directly from its own RES units, it has the ability to consume energy (by pumping) directly from the network during the night. This energy is considered as energy that absorbed from the network, and is billed in a different way. Table 5 shows the different billing options that exist in PHS operation, according the Greek legislative framework. 
Table 5. Billing options for PHS system

\begin{tabular}{|l|c|}
\hline Energy delivered by the hydro turbines & $236 € / \mathrm{MWh}$ \\
\hline Energy delivered by the WFs directly to the network & $100 € / \mathrm{MWh}$ \\
\hline Energy absorbed from the network & $186 € / \mathrm{MWh}$ \\
\hline Power availability & $127,000 € / \mathrm{MW}$ \\
\hline
\end{tabular}

\section{B. Results and discussion}

In order to evaluate the effect of Malia PHS installation in Cretan power system operation, two scenarios (referred as scenario 1 and scenario 2) have been considered. Scenario 1 represents a modest case study that takes into account only the guaranteed daily operation of hydro power station $(75 \mathrm{MW} \times 8$ hours per day), which results an annual electricity production of $220 \mathrm{GWh}$. By considering a total PHS system efficiency of $72 \%$, the electricity needed for pump operation is $304 \mathrm{GWh}$. The simulation results show that $88 \%$ of this electricity is covered from the WFs of PHS system. From the remaining produced WFs electricity, 5.5\% is delivered directly to the network, whereas $6.5 \%$ cannot be absorbed.

Table 6 presents the economical and environmental results from PHS system operation, considering scenario 1 . The economical indices include net present value (NPV), after tax internal rate of return (IRR with $29 \%$ tax rate), benefit to $\operatorname{cost}(\mathrm{B} / \mathrm{C})$ ratio, simple payback and equity payback for discount rate $i=6 \%$. The considered costs are 3,000,000 €/MW for PHS system construction (without the WFs) and 1,200,000 €/MW for WTs. The 75\% of these initial costs are covered from a bank loan of $7 \%$ interest rate. Total annual operational and maintenance (O\&M) costs are assumed to be $2 \%$ of the initial cost (these costs do not include the cost of absorbed electricity from the network). The total lifetime of the project is considered to be 40 years [13]. Due to the fact that WFs lifetime is approximately 20 years, reinstallation of equal capacity WTs is considered during halftime of the project life. The environmental results show the amount of annual greenhouse gases (GHGs) emission reduction for the specific fuel mix of Cretan power system (see also Table 2).

Table 6. Economical and environmental evaluation of PHS project of Malia (scenario 1)

\begin{tabular}{|l|c|}
\hline NPV & $60,710,000 €$ \\
\hline IRR (after tax) & $8.8 \%$ \\
\hline B/C ratio & 1.49 \\
\hline Simple payback & 10.3 years \\
\hline Equity payback & 11.2 years \\
\hline Annual GHG emission reduction & 162,000 tn $\mathrm{CO} 2_{\mathrm{eq}}$ \\
\hline
\end{tabular}


Table 7. Economical and environmental evaluation of PHS project of Malia (scenario 2)

\begin{tabular}{|l|c|}
\hline NPV & $244,760,000 €$ \\
\hline IRR (after tax) & $15.2 \%$ \\
\hline B/C ratio & 2.54 \\
\hline Simple payback & 8.4 years \\
\hline Equity payback & 6.4 years \\
\hline Annual GHG emission reduction & 239,000 tn $\mathrm{CO} 2_{\mathrm{eq}}$ \\
\hline
\end{tabular}

Scenario 2 represents a more realistic case study, in which the operation of Cretan power system was simulated for one year by using the methodology that described in Section IV, taking into account the technical characteristics of Malia PHS station (Section V.A). The simulation results show that on annual basis the hydro turbine produces $330 \mathrm{GWh}$ of electricity, whereas the electricity needed for pump operation is $458 \mathrm{GWh}$. The results also show that $83 \%$ of this electricity is covered from the WFs of PHS system. From the remaining produced WFs electricity, $8 \%$ is delivered directly to the network, whereas $9 \%$ cannot be absorbed. Table 7 presents the economical and environmental results from PHS system operation, regarding scenario 2.

The comparison of results show that in scenario 2 the annual electricity production is $50 \%$ higher, which is equivalent to a mean daily operation of hydro power station at full power for 12 hours per day. The study of economical indicators (in Tables 6 and 7) shows that the installation of a PHS station at Malia is economically viable even in the modest scenario. Moreover, the achieved annual GHG emission reduction is significant in both cases.

\section{Conclusion}

In this paper, the effect of PHS units installation on the (largest in Greece) autonomous power system of Crete Island is examined. The analysis showed the significant effect of PHS units operation on the energy mix, as it produces $7.5 \%$ of total energy production in Crete considering a modest scenario, and more than $10 \%$ considering a more representative scenario. Moreover, the analysis proved that the project is economically attractive, while it provides significant environmental benefits. The viability of this project also shows that additional PHS stations can be installed in the Cretan power system, increasing the wind power penetration and decreasing the dependence on expensive fossil fuels (diesel and mazut). 


\section{References}

[1] Hatziargyriou, N. D., Tsikalakis, A., Androutsos, A. "Status of distributed generation in the Greek islands." Paper presented at the 2006 IEEE PES General Meeting, Montreal, Canada, 2006.

[2] Papadogiannis, K. A., Karapidakis, E. S., Hatziargyriou, N. D. "Cost allocation of losses in autonomous power systems with high penetration of RES.” WSEAS Transactions on Power Systems 4(6) (2009): 210-220.

[3] Tsikalakis, A., Hatziargyriou, N., Papadogiannis, K., Gigantidou, A., Stefanakis, J., Thalassinakis, E. "Financial contribution of wind power on the island system of Crete." Paper presented at the RES for Islands Conference, Crete, 2003.

[4] Karapidakis, E. S., Hatziargyriou, N. D. "Online preventive dynamic security of isolated power systems using decision trees." IEEE Transactions on Power Systems 17(2) (2002): 297-304.

[5] Kymakis, E., Kalykakis, S., Papazoglou, T. "Performance analysis of a grid connected photovoltaic park on the island of Crete." Energy Conversion and Management 50(3) (2009): 433-438.

[6] Hellenic Electricity Distribution Network Operator S.A. Annual release of Cretan power system operation - year 2014. HEDNO S.A., 2015. (in Greek)

[7] Fox, B., Flynn, D., Bryans, L., Jenkins, N., Milborrow, D., O’Malley, M., Watson, R., Anaya-Lara, O. Wind Power Integration - Connection and system operational aspects. London, UK: IET, 2007.

[8] Ter-Gazarian, A. G. Energy Storage for Power Systems (2 ${ }^{\text {nd }}$ Edition). London, UK: IET, 2011.

[9] Simopoulos, D. N., Kavatza, S. D., Vournas, C. D. "Unit commitment by an enhanced simulated annealing algorithm." IEEE Transactions on Power Systems 21(1) (2006): 68-76.

[10] Katsigiannis Y. A., Karapidakis, E. S. "Comparing Different Approaches to Solve the Unit Commitment Problem Considering Hydro-Pumped Storage Stations." Paper presented at the International Workshop on Deregulated Electricity Market Issues in South-Eastern Europe (DEMSEE'07), Instanbul, Turkey, 2007.

[11] Kazarlis, S. A., Bakirtzis, A. G., Petridis, V. "A genetic algorithm solution to the unit commitment problem." IEEE Transactions on Power Systems 11(1) (1996): 83-92.

[12] Regulatory Authority of Energy. Greek grid code of non interconnected islands. RAE, 2014. (in Greek) 
[13] Kousksou, T., Bruel, P., Jamil, A., El Rhafiki, T., Zeraouli, Y. "Energy storage: Applications and challenges." Solar Energy Materials and Solar Cells 120 (2014): 59-80. 